\title{
O PLANEJAMENTO NA CURADORIA DIGITAL
}

\author{
PLANNING IN DIGITAL CURATION
}

Sandra de Albuquerque Siebra ${ }^{1}$

Faysa de Maria Oliveira e Silva²

Rosa Guadalupe de la Vega ${ }^{3}$

\begin{abstract}
RESUMO
Reflete sobre o planejamento no contexto da curadoria digital. Esta é uma pesquisa descritiva e qualitativa, que faz uso da pesquisa bibliográfica e documental. Como resultados, foram definidas seis dimensões que devem ser exploradas no planejamento e os elementos dentro delas, independente do tipo de objeto digital a ser curado, foram elas: infraestrutura, recursos financeiros, recursos humanos, ações relacionadas com preservação digital, questões legais e éticas e questões relacionadas ao acesso e uso dos objetos digitais. Foram indicados documentos que devem ser produzidos durante o planejamento para orientar as equipes do projeto, como o Plano de Preservação Digital e, também, foi ressaltada a importância da participação da comunidade alvo do projeto de curadoria nesta etapa. Por fim, foi verificado que as descrições sobre planejamento, na maioria dos modelos de curadoria digital é ainda sucinta, técnica e superficial e podem não dar apoio suficiente para a realização do planejamento da curadoria por parte das instituições/organizações. Conclui-se que é necessário que os profissionais da informação estejam aptos a elaborar materiais para suprir essa lacuna e para orientar a implementação de projetos de curadoria digital.

Palavras-Chave: Planejamento para Curadoria Digital. Modelos de ciclos de vida. Curadoria Digital. Etapa de Planejamento. Preservação Digital.
\end{abstract}

\begin{abstract}
Reflects on planning in the context of digital curation. This is a descriptive and qualitative study, which uses bibliographic and documentary research. As a result, six dimensions were defined that should be explored in the planning and the elements within them, regardless of the type of digital object to be cured, they were: infrastructure, financial resources, human resources, actions related to digital preservation, legal and ethical issues and issues related to access and use of digital objects. Documents were indicated that must be produced during the planning to guide the project teams, such as the Digital Preservation Plan and, also, the importance of the participation of the target community of the curation project at this stage was emphasized. Finally, it was found that the descriptions of planning, in most digital curation models, are still succinct, technical and superficial and may not provide sufficient support for the realization of curatorship planning by institutions / organizations. It is concluded that it is necessary that information professionals are able to develop materials to fill this gap and to guide the implementation of digital curation projects.
\end{abstract}

Keywords: Planning for Digital Curation. Lifecycle Models. Digital Curation. Planning Stage. Digital Preservation.

Artigo submetido em 26/11/2020 e aceito para publicação em 09/12/2020

\footnotetext{
1 Doutora em Ciência da Computação pela Universidade Federal de Pernambuco, Brasil. Docente no Programa de Pós-Graduação em Ciência da Informação. Universidade Federal de Pernambuco, Brasil. ORCID https://orcid.org/0000-0002-0078-6918. E-mail: sandra.siebra@gmail.com. 2 ORCID https://orcid.org/0000-0003-0127-6693. E-mail: faysa.oliveira@ufpe.br.

3 Mestranda no Programa de Pós-Graduação em Ciência da Informação. Universidade Federal de Pernambuco, Brasil. ORCID https://orcid.org/0000-0002-7651-1806. E-mail: rosa.vega@ufpe.br.
} 


\section{INTRODUÇÃO}

O avanço tecnológico ocorrido nos últimos anos, associado: 1) ao fato que o usuário da atualidade é produtor e consumidor de dados e informações em diferentes sistemas, aplicativos e plataformas, e valoriza a colaboração e o reuso de dados; 2) ao aumento exponencial na produção de objetos digitais; 3) à obsolescência tecnológica decorrente da evolução das tecnologias; 4) aos riscos diversos aos quais os objetos digitais estão submetidos (ex: falha de hardware e vírus), tem ampliado a discussão da importância de se ter garantida a preservação e acesso a longo prazo aos objetos digitais, sejam eles documentos (arquivísticos, multimídia, sonoros, etc) ou dados (governamentais, de pesquisa, etc).

Porém, organizar, armazenar, gerenciar, preservar e dar acesso à dados e informações digitais, de forma eficiente e eficaz, com a garantia de autenticidade e integridade, apesar de ser uma necessidade, é um desafio. O que endossa o destacado por Siebra, Borba e Miranda (2016, p.3) que urge "a aplicação de ações e estratégias efetivas que possibilitem a preservação e acesso a longo prazo às informações digitais", e, segundo os mesmos autores, também urge a "preparação de recursos humanos capacitados, em quantidade suficiente para enfrentar os desafios de gerenciar um grande volume de informação digital, em formatos e suportes diversos" (p.3).

Neste cenário, ressalta-se a importância da curadoria digital que envolve a gestão planejada e intencional, adição de valor e a preservação de objetos digitais durante todo o ciclo de vida destes, tendo como perspectiva o desafio de promover o acesso, uso e reuso, a fim de atender às gerações atuais e futuras (TIBBO; HANK; LEE, 2008; ABBOT, 2008; SIEBRA; BORBA; MIRANDA, 2016; SAYÃO; SALES, 2020). O que faz com que a curadoria digital englobe ações gerenciais, técnicas, tecnológicas e políticas.

Para a implementação da curadoria digital vem sendo utilizados modelos de ciclos de vida, sendo um dos mais famosos o do Digital Curation Centre - DCC (DCC, c2004-2020). Porém, nos modelos existentes observa-se a falta de detalhamento das ações a serem realizadas em cada etapa do ciclo, o que pode fazer com que as instituições tenham dúvidas sobre como colocar em prática algum destes modelos. Além disso, alguns modelos não explicitam ou são muito sucintos e/ou técnicos em uma etapa que é fundamental para o sucesso e eficácia de todas as demais etapas de um ciclo de curadoria digital: o planejamento. 
O planejamento na curadoria digital pode ser definido como o processo pelo qual as necessidades gerais e específicas relacionadas à curadoria de uma coleção/acervo/conjunto de dados são identificadas, prioridades são determinadas e os recursos para implementação do ciclo de curadoria digital, como um todo, são definidos (KUMAR, 2011). Logo, esta pode ser considerada uma etapa basilar e engloba a definição e especificação de questões relacionadas à recursos financeiros, tecnológicos, materiais e humanos; a documentação de questões legais e éticas; além da seleção e adoção de políticas, definição de procedimentos, dos meios e dos métodos necessários para alcançar os objetivos previamente definidos para um projeto de curadoria (CHIAVENATO, 2014).

Assim, compreendendo a importância do planejamento para a curadoria digital, questiona-se: Que ações necessitam ser realizadas nesta etapa? Quais documentos precisam ser produzidos? Como os ciclos de vida para curadoria digital abordam a etapa de planejamento? Nesse contexto, o objetivo geral desta pesquisa foi refletir sobre o planejamento no contexto da curadoria digital.

Como contribuição social, espera-se que esta pesquisa possa colaborar para a implementação da etapa de planejamento da curadoria em instituições e/ou organizações e trazer esclarecimentos sobre esta etapa para os profissionais envolvidos em projetos de curadoria digital. Como contribuição para a área de Ciência da Informação, esta pesquisa colabora com material sobre o planejamento para curadoria digital. Pois, como afirmam Sanchez, Vidotti e Vechiato (2017, p. 14-15), "Curadoria Digital dentro do cenário da Ciência da Informação é ainda um assunto novo e em expansão, que necessita da realização de estudos para aprofundamento no tema". Realmente, há escassez de material em língua portuguesa sobre curadoria digital, em especial sobre planejamento para curadoria. Até a presente data, foi encontrada apenas uma iniciativa de detalhamento do planejamento em Mello (2020), que o descreve brevemente e ainda de forma superficial esta etapa na sua proposta de modelo para a preservação e curadoria digital de objetos digitais de centros de pesquisas oncológicas.

\section{CURADORIA E PRESERVAÇÃO DIGITAL}

Em 1997, Hedstrom definiu preservação digital como "o planejamento, alocação de recursos, e aplicação de estratégias de preservação e das tecnologias necessárias para garantir que a informação digital de valor permaneça acessível e passível de uso" (p. 190). O que é endossado por Flores (2017, p. 74) quando afirma que "A preservação digital caracteriza-se no desenvolvimento teórico e na aplicação de técnicas capazes de viabilizar a permanência, garantindo o acesso e a autenticidade dos objetos 
digitais". A partir de meados de 2004, o conceito de preservação digital passou a ser trabalhado dentro de um contexto mais amplo, o da curadoria digital, que engloba, também, questões relacionadas à gestão dos objetos digitais, à adição de valor a eles e ao arquivamento digital dos mesmos (SIEBRA; BORBA, 2018).

Assim, a curadoria digital abrange "o que vem antes da preservação e o que vem depois - ou seja, como os dados são criados e como são usados [...] e como serão usados e por quem, no futuro" (HARVEY, 2010, p. 16). O que é reafirmado por Yakel (2007) e Caplan(2011), quando registram que a curadoria digital engloba todo o ciclo de vida dos objetos digitais, sendo a preservação um ponto específico deste ciclo.

A curadoria digital foi concisamente definida por Rusbridge et al. (2005, p. 3) como "a gestão ativa dos dados ao longo do ciclo de vida de interesse acadêmico e científico; é a chave para a reprodutibilidade e reutilização". Para Abbott (2008), a curadoria digital é o gerenciamento e preservação de dados digitais a longo prazo e envolve atividades de gerenciamento, desde o planejamento da criação de dados e informações, passando por melhores práticas em digitalização e documentação, pela garantia de disponibilidade e adequação para descoberta e reutilização no futuro. O que coaduna com as definições dadas, posteriormente, por Tibbo, Hank e Lee (2008, p. 235), que colocam a curadoria como "gestão ativa e preservação de recursos digitais ao longo do seu ciclo de vida completo". E, também pela National Academy of Science (2015), que define curadoria como o gerenciamento ativo e o aprimoramento de ativos de informação digital, para uso atual e futuro. Pode-se dizer que essas definições foram unidas por Oliver e Harvey quando especificam que

\footnotetext{
A curadoria digital está preocupada com o gerenciamento ativo de dados, enquanto continuar a ser de interesse acadêmico, científico, de pesquisa, administrativo e / ou pessoal, com o objetivos de dar suporte a reprodutibilidade, reutilização e agregação de valor a esses dados, gerenciá-los desde o seu ponto de criação até que seja determinado que ele não será mais útil, e garantir sua acessibilidade, preservação, autenticidade e integridade ao longo do tempo. (OLIVER; HARVEY, 2016, p. 8).
}

Em todas essas definições é possível ver a menção à curadoria como uma gestão ativa ou a menção explícita ao planejamento. Para National Academy of Science (2015) e Siebra, Borba e Miranda (2016), a gestão ativa indica que as ações devem ser planejadas, intencionais, sistemáticas, objetivas e direcionadas, de forma que tornem as informações digitais adequadas a um propósito. Assim, a gestão ativa acaba por envolver atividades coordenadas que permitam aos usuários compreender e explorar a informação digital. Além de atividades gerenciais, técnicas, tecnológicas e políticas que busquem garantir a integridade das informações digitais, e, também, que elas permanecerão encontráveis, acessíveis, 
autênticas e passíveis de serem usadas, enquanto os usuários em potencial tiverem a necessidade ou o direito de usá-las (NATIONAL ACADEMY OF SCIENCE, 2015). Destaca-se que este tipo de gestão "ajuda a garantir que a autenticidade de um recurso informacional sobreviva no tempo, apesar das transformações tecnológicas, com uma perda mínima de conteúdo informativo, de funcionalidade e de acessibilidade" (TAMMARO; SALARELLI, 2008, p.196).

Porém, fazer uma gestão intencional e ativa demanda um planejamento meticuloso (OLIVER; HARVEY, 2016). O que já é considerado em diversos modelos de ciclo de vida, que vem sendo utilizados para guiar/orientar a realização das atividades de curadoria digital, que explicitam, mesmo que de forma superficial, uma etapa de planejamento. Modelos tais como o JISC - Joint information systems committee model (BEAGRIE, 2004); Digital Curation Lifecycle Model do Digital Curation Centre (DCC, c2004-2020); DCC\&U - Extended digital curation lifecycle model (CONSTATOUPOULOS et al., 2009); UK Data Archive Data Lifecycle (2010) e DataOne Data Lifecycle (2012). Além do Open Archival Information System - OAIS, o qual foi tomado como base pela maioria dos modelos de ciclo de vida, e que tem 0 planejamento da preservação (preservation planning) como um dos seus elementos (LAVOIE, 2014).

Observa-se que "os modelos são estruturalmente desiguais quanto a sua complexidade e detalhamento, no entanto desempenham funções similares quando se trata de procedimentos curatoriais" (SILVA; SIEBRA, 2017). E, apesar do planejamento dever ser tomado como um prérequisito para o gerenciamento e administração da curadoria e preservação de objetos digitais, para garantir a longevidade dos objetos, sua autenticidade e que eles permaneçam acessíveis a longo prazo, nem todos os modelos detalham essa etapa, como será visto posteriormente neste artigo. Porém, antes, na seção a seguir, serão definidos conceitos básicos sobre planejamento.

\section{NOÇÕES BÁSICAS SOBRE PLANEJAMENTO}

O planejamento é definido como um processo que considera os objetivos e os recursos, visando alcançar uma situação desejada, da maneira mais eficiente e efetiva (MAXIMINIANO, 2010; OLIVEIRA, 2018). Ele deve nortear a organização para seguir o rumo traçado, de forma a buscar uma situação almejada, diferente da atual, empregando todo o potencial disponível (OLIVEIRA, 2018).

Para Chiavenato (2014), o planejamento possibilita a definição dos objetivos organizacionais em função dos recursos necessários para alcançá-los, de maneira eficaz. De fato, o planejamento auxilia na organização de um projeto, principalmente "na seleção e adoção da política, dos procedimentos, dos 
meios e dos métodos necessários para alcançar os objetivos previamente definidos". (CHIAVENATO, 2014, p.105). Por isso mesmo, o planejamento deve ser tido como a primeira etapa de qualquer projeto e, se bem realizado, pode auxiliar na redução dos riscos e desafios a serem superados.

De acordo com Maximiano (2010), o processo de planejamento compreende três etapas: análise, avaliação de opções e seleção do curso da ação, onde cada uma delas requer decisões dos responsáveis pelo planejamento. E fatores como a disponibilidade de informações sobre cenários, contexto, produtos, equipes, recursos irão influenciar as decisões a serem tomadas. Logo, a fim de realizar o planejamento, é preciso ter informações sobre o projeto a ser realizado e o conhecimento de técnicas e modelos de planejamento em si. É preciso projetar cenários futuros e registrar como agir em cada um deles, considerando ameaças, oportunidades e riscos. Por fim, o processo de planejamento em si pode ser realizado e decisões poderão ser tomadas e registradas em planos que devem englobar desde os objetivos do projeto em si, até questões relacionadas à infraestrutura, à adoção de padrões, recursos financeiros e humanos, assim como a especificações de critérios de avaliação do projeto, para ver o quanto o planejamento foi efetivo ou não.

Além disso, é importante frisar que um processo de planejamento adequado deve prever treinamentos necessários e a disponibilização de ajuda técnica aos profissionais envolvidos, além de fomentar debates na organização para ajustar o ambiente ao desenvolvimento do trabalho, de forma adequada e produtiva. Adicionalmente, destaca-se que todas as definições e decisões tomadas devem ser documentadas, pois "a documentação é parte do planejamento" (ICPSR, 2005, p.5).

A aplicação de um modelo/ciclo de curadoria pode ser considerado um projeto dentro das instituições e, como tal, requer planejamento. E este planejamento deve atender aos objetivos da instituição/organização; às políticas nela existentes; aos recursos e tempo disponíveis e às especificidades dos acervos a serem curados (ex: tipo de material, público alvo, etc). Só assim o projeto de curadoria poderá ser implementado de forma eficiente e com o mínimo de imprevistos.

\section{METODOLOGIA}

De caráter qualitativa, se caracteriza quanto aos fins como descritiva e quanto aos meios como bibliográfica (MICHEL, 2015). O levantamento bibliográfico na pesquisa descritiva cria o conhecimento necessário para realizar o estudo, ao se propor a verificar e explicar problemas e fatos da vida real, observar e fazer relações e conexões à luz da influência que 0 ambiente exerce sobre estes problemas e fatos (MICHEL, 2015). 
Para o levantamento bibliográfico, foram utilizadas as bases de dados: BRAPCI (para ter um panorama do contexto nacional) e SCOPUS (para um panorama estrangeiro) com a delimitação de período temporal de 2008 a 2020, e o tipo de documento artigo, anais de evento, livro e capítulo de livro. Também foram consultados livros internacionais que abordavam a temática pesquisada, adquiridos em formato de ebook. Foram utilizados os termos de busca planejamento e curadoria digital e, também, planejamento e preservação digital, em inglês e em português.

Os materiais que se mostraram alinhados com a temática de pesquisa foram selecionados, conforme pode ser visto no Quadro 1, a partir da leitura do título, resumo (abstract), palavras chaves e, algumas vezes, da introdução do artigo (se o resumo não era informativo o suficiente).

Quadro 1 - Artigos Recuperados no Levantamento Bibliográfico

\begin{tabular}{|l|c|c|c|c|}
\hline \multirow{2}{*}{ Termos } & \multicolumn{2}{c|}{ SCOPUS } & \multicolumn{2}{c|}{ BRAPCI } \\
\cline { 2 - 5 } & Recuperados & Selecionados & Recuperados & Selecionados \\
\hline $\begin{array}{l}\text { Digital curation and } \\
\text { Planning }\end{array}$ & 23 & 9 & 1 & 1 \\
\hline $\begin{array}{l}\text { Curadoria Digital e } \\
\text { Planejamento }\end{array}$ & 2 & 0 & 4 & 3 \\
\hline $\begin{array}{l}\text { Digital Preservation and } \\
\text { Planning }\end{array}$ & 1 & 1 & 0 & 0 \\
\hline $\begin{array}{l}\text { Preservação Digital e } \\
\text { Planejamento }\end{array}$ & 2 & 0 & 17 & 5 \\
\hline
\end{tabular}

Fonte: Dados da Pesquisa, 2020

Na SCOPUS, os nove artigos selecionados abordavam o planejamento de maneiras diversificadas: planejamento em curadoria digital, planejamento em gerenciamento de dados, planejamento da custodia de dados e planejamento dos custos para curadoria digital.

Destaca-se que na BRAPCI, os artigos selecionados em português para os termos curadoria digital e planejamento exploram o planejamento de maneira muito breve e superficial. Os termos preservação e planejamento em português recuperaram 17 artigos, porém três já estavam na busca anterior e um estava representado duas vezes na base. Assim, dos 13 restantes apenas 5 se relacionavam à temática. O uso dos termos em inglês trouxe apenas um artigo diferentes dos que já haviam sido recuperados.

Os materiais selecionados foram lidos na íntegra. O levantamento bibliográfico e as leituras foram realizados no período de setembro a outubro/2020. Adicionalmente, foi realizada uma análise documental em manuais, guias, normativas e planos de preservação digital para complementar 0 embasamento teórico desta pesquisa. A partir de todas as informações levantadas, foram definidos 
elementos a serem contemplados no planejamento de projetos de curadoria digital e foi analisada a etapa de planejamento dos modelos de ciclo de vida mais citados na literatura consultada.

\section{PLANEJAMENTO NA CURADORIA DIGITAL}

De acordo com Oliver e Harvey (2016), o planejamento de cada etapa de um ciclo de vida de curadoria é essencial. Isso engloba: o planejamento do que é necessário em cada etapa do ciclo; desenvolver planos de ação para todas as etapas do ciclo, assim como definir uma periodicidade para revisar e atualizar os procedimentos de curadoria planejados e as decisões que foram tomadas. De fato, o planejamento deve ser a primeira etapa de qualquer projeto de curadoria e/ou preservação digital, independente da natureza dos objetos curados (SANTOS; FLORES, 2015). Ele precisa contemplar todas as atividades relacionadas à curadoria destes objetos, desde a inserção deles no processo de curadoria até a sua destinação final, abordando elementos relacionados à gestão, representação da informação, preservação, elaboração de políticas e normativas e às tecnologias que se façam necessárias. Além da definição de recursos financeiros e humanos (GRÁCIO, 2011), de padronizações e questões legais como as relacionadas aos direitos autorais (FERREIRA, 2006), como também a definição de critérios para seleção e avaliação dos objetos passíveis de preservação (CAVALCANTI; SALES, 2016). Adicionalmente, é importante na etapa de planejamento realizar uma análise de riscos (BARATEIRO et al., 2010; TAVARES, 2014), de forma que eles possam ser identificados e sejam definidas ações para mitigá-los. Um risco refere-se à probabilidade de ocorrência de um evento que pode conduzir a organização a um resultado desfavorável (TAVARES, 2014).

Antes de partir para o detalhamento do que deve ser abordado na etapa de Planejamento de um projeto de curadoria digital, é preciso que sejam definidos os objetos digitais que serão curados, pois o tipo dos objetos digitais (ex: documentos arquivísticos, dados de pesquisa, etc), sua quantidade e suas especificidades tem impacto direto nas decisões que precisarão ser tomadas. Também é preciso ter claramente especificados quais são os objetivos da instituição/organização com a curadoria deste objetos, além de ser importante conhecer as políticas e normativas já existentes na instituição que possam afetar o planejamento do projeto de curadoria (ex: política de informação, política de preservação digital, etc). Outro ponto que pode contribuir com o planejamento é conhecer a comunidade alvo que se beneficiará com a curadoria dos objetos, pois isso contribuirá com a melhor definição das formas de promover o acesso e uso dos objetos curados. 
A seguir serão definidas as dimensões a serem contempladas no planejamento e que elas envolvem.

\subsection{Dimensões do Planejamento}

Nesta pesquisa as questões de planejamento foram divididas em dimensões: infraestrutura, recursos financeiros, recursos humanos, ações relacionadas com preservação, questões éticas e legais e questões relacionadas ao acesso e uso dos objetos digitais. Todas elas serão descritas a seguir.

Planejamento da Infraestrutura - envolve os recursos estruturais necessários para a implementação de projetos de curadoria pode ser subdividida em: infraestrutura física e tecnológica.

- Infraestrutura Física - relaciona-se com o espaço físico onde o projeto de curadoria digital se desenvolverá que deve estar, a priori, longe de áreas de riscos (ex: áreas passíveis de inundação). Tanto o espaço que será ocupado pelos recursos humanos que comporão a equipe do projeto, quanto o espaço que será reservado para acomodar a infraestrutura tecnológica. Esse ambiente físico, em especial este último, deve estar sob temperaturas adequadas (uso de arcondicionado), estar protegido contra o acesso de pessoas não autorizadas, ter instalações elétricas e de dados segundo normas estabelecidas, de forma a evitar problemas e, sempre que possível ter equipamentos extras de segurança para o ambiente tais como: detectores de fumaça, nobreaks, câmeras de monitoramento, geradores de energia e fechadura com trava elétrica ou reconhecimento por digital para restrição do acesso (GRACIO, 2011). Adicionalmente, é importante que procedimentos de manutenção sejam definidos e sua periodicidade registrada, em especial procedimentos de manutenção preventiva. Registra-se que esse é um ponto geralmente crítico, especialmente em instituições públicas.

- Infraestrutura Tecnológica - refere-se a toda a infraestrutura de hardware e software (ex: ferramentas, sistemas, scanners se for necessária a digitalização do acervo), inclusa a infraestrutura de redes de computadores e conexão com a internet, de armazenamento e para disseminação da informação (ex; repositórios digitais ou repositórios digitais confiáveis). Também, a especificação de rotinas de backup confiáveis e a especificação de mecanismos de segurança (ex: controle de acesso, uso de senhas, etc), capazes de atender às demandas técnicas necessárias para preservar os objetos digitais selecionados (GRÁCIO, 2011). Engloba 
a infraestrutura de preservação que visa preservar os objetos digitais e seus metadados; e a infraestrutura de acesso voltada para atender às buscas realizadas pelos usuários.

Planejamento dos recursos financeiros - as instituições precisam planejar os custos que es- tão envolvidos no processo de curadoria digital. Ou seja, o quanto elas têm disponível para investir no projeto, e o quanto elas terão a longo prazo (KOWALCZYK, 2018). Como a curadoria digital requer disponibilidade constante de recursos financeiros, "é importante que exista uma po- lítica permanente de investimento por parte da instituição, em que os custos da curadoria façam parte do orçamento anual" (GRACIO, 2011, p. 91), de forma que a atualização, expansão e/ou manutenção de hardware e software; a capacitação das pessoas envolvidas no projeto; além de investimentos nos procedimentos de preservação possam ser garantidos.

De acordo com Gracio (2011, p. 91), "deve-se procurar garantir as verbas e investimentos necessários para execução do projeto de curadoria digital, pois esse é um projeto 'para toda vida', visto que há dados e objetos digitais de valor permanente". Porém, o próprio autor adverte que nem sempre será trivial conseguir este investimento permanente, "depende muito da prioridade que a instituição confere às questões de curadoria digital” (p. 91). Adicionalmente, é importante que a equipe envolvida esteja atenta a formas alternativas de levantamento de verbas como a busca por investimentos ou financiamentos externos e a participação em editais (comuns em instituições públicas). Outra possibilidade para contribuir com a execução e/ou sustentabilidade de projetos de curadoria é a formação de parcerias ou de redes de colaboração entre instituições/organizações. Um exemplo desta última é a Rede Memorial de Pernambuco (RMP), onde instituições memoriais pernambucanas desenvolvem projetos colaborativos de preservação e/ou curadoria digital, compartilhando recursos humanos e tecnológicos, além de saberes e capacidades específicas de cada parte (TAVARES; LIMA, 2017),

Planejamento dos recursos humanos necessários para realização do projeto de curadoria. É fato que projetos de curadoria envolvem conhecimentos diversificados (administrativos, técni-cos, tecnológicos e legais), o que faz com que, dificilmente, um único profissional tenha domí-nio sobre todo o conhecimento necessário ao projeto. Dessa forma, é comum a montagem de equipes multidisciplinares, compostas, por exemplo, por bibliotecários, arquivistas, gestores da informação, além de profissionais das áreas de Sistemas de Informação, Direito e Adminis- 
tração. Gracio (2011, p. 89) frisa que, uma vez que a equipe esteja definida, é preciso "definir o papel de cada um dos envolvidos, com o objetivo de identificar e apontar responsabilidades". Ou seja, é preciso especificar quais perfis são necessários para execução das etapas de curadoria; que habilidades e conhecimentos esses perfis devem possuir e quais responsabilidades serão a eles designadas, de forma documentada. Destaca-se aqui a relevância de oferecer treinamento e capacitação aos envolvidos nos projetos de curadoria (NATIONAL ACADEMY OS SCIENCE, 2015), tanto no início do projeto, quanto periodicamente, de forma que os profissionais possam atualizar seus conhecimentos técnicos, diante das constantes evoluções dos recursos tecnológicos. Vale destacar que, especialmente em órgãos públicos, há um problema que rotineiramente é enfrentado, que é a rotatividade de equipes de projeto, devido ao fato de existirem bolsistas e estagiários que possuem tempo limitado de atuação no projeto. O que acaba por gerar a necessidade de se estar preparado para oferecer capacitação a cada nova entrada de componente da equipe e de que sejam documentados os principais fluxos de trabalho, para facilitar a chegada de novos integrantes. Uma forma de amenizar o impacto dessa rotatividade, é a criação de cartilhas, manuais, tutoriais, contendo informações sobre o fluxo de trabalho, padrões, metodologias e ferramentas adotados na implementação do projeto de curadoria, que possam ser utilizados pelos novos integrantes.

Planejamento das ações relacionadas com preservação digital, levando em conta que, segundo Roncaglio et al. (2004, p.10), "a preservação deve considerar as técnicas corretas e específicas para os diferentes suportes, tendo sempre em vista prolongar o máximo possível seu tempo de vida". Assim, essa dimensão de planejamento abrange:

- A definição de padrões (ex: padrões de metadados, padrão de nomenclatura para os arquivos, formatos de arquivos padrão para cada tipo documental), de metodologias, de procedimentos (ex: critérios para análise e seleção de objetos para entrar no ambiente de curadoria) e de fluxos de trabalho (OLIVER; HARVEY, 2016; HARVEY, 2010). Chama-se a atenção aqui para a importância da escolha do padrão de metadados, a fim de garantir acesso e reutilização ao longo do tempo (KOWALCZYK, 2018). Realmente, o planejamento é necessário para escolher o metadado mais adequado a cada tipo específico de objeto digital e, assim, representa-lo de forma entendível, facilitando a busca pelo mesmo. (OLIVER, HARVEY, 2016). Destaca-se. Aqui, também que os 
formatos de arquivos utilizados devem ser formatos de arquivo abertos, uma vez que eles são mais adequados do que os fechados ou chamados formatos proprietários, porque a maneira que eles codificam o conteúdo é transparente (RIMKUS et al, 2014). Adicionalmente, ressaltase que é preciso definir o uso de identificadores persistentes para proporcionar uma melhor encontrabilidade do objeto digital.

- A documentação dos fluxos de trabalho em cada etapa do processo de curadoria (por exemplo: qual o fluxo de trabalho para digitalizar fotografias, qual o fluxo para recebimento dos dados advindo de outros sistemas, como se deve realizar a descrição/contextualização dos objetos, ou seja, como deve ser o passo a passo destes procedimentos);

- A elaboração de políticas que incluam ou excluam a informação do ciclo de curadoria (select e appraise)

- A escolha da(s) estratégia(s) de preservação a serem adotados (ARELLANO, 2004), sua periodicidade e possíveis "gatilhos" (eventos que acabam por antecipar a aplicação de estratégias de preservação, tal como uma nova tecnologia que surge, que dispara a necessidade de mudança da mídia de armazenamento);

- A criação de templates de documentos para deixar o processo mais padronizado, (por exemplo: modelo de termo de custódia, termo de cessão de direitos autorais, entre outros).

- $\quad E$, adicionalmente, riscos que podem atingir o projeto e os objetos digitais foco da curadoria devem ser mapeados, analisados e geridos, para assim, sanar os possíveis problemas que possam surgir. Para cada risco identificado deve ser mensurada a sua probabilidade de ocorrer e que medidas serão tomadas, caso ele ocorra (TAVARES, 2014).

$>$ Planejamento de questões legais e éticas - segundo Kowalczyk, (2018), as questões éticas e legais também devem ser incorporadas ao planejamento. A requisição de assinatura de declaração de consentimento no caso de dados recebidos ou doados; a observação de se os objetos possuem direitos de propriedade intelectual; se possuem dados sensíveis que precisem ser anonimizados; se há restrições de acesso que precisem ser atendidas ou a forma de licenciamento para uso (KOWALCZYK, 2018). Esta dimensão também envolve a elaboração de instrumentos legais, tais como termo de cessão de direitos autorais e termos de custódia, além da documentação de como normativas e políticas existentes na instituição ou em âmbitos municipal, estadual ou federal que afetam o projeto de curadoria serão atendidas. 


\section{Planejamento de questões relacionadas ao acesso e uso dos objetos digitais - abrange} questões relacionadas a: como se dará o acesso aos objetos, se há objetos sigilosos, quais os níveis de acesso que existirão e como esses objetos serão apresentados aos usuários, como 0 usuários farão uso dos objetos. Para melhor atender às necessidades de informação dos usuários, questões de usabilidade, arquitetura da informação e acessibilidade podem ser trabalhadas.

Adicionalmente, entende-se que, após a realização de um planejamento inicial, que deve envolver além da equipe multidisciplinar do projeto de curadoria, representantes do público alvo que se beneficiará da preservação e disponibilização dos objetos digitais, é preciso descrever e acompanhar as atividades sendo implementadas. E, a partir daí, alterar e corrigir as falhas e registrar as lições aprendidas, após a execução. Também, é preciso que seja especificada uma periodicidade de reavaliação de todo o processo de curadoria e, como indica Kowalczyk (2018), documentar todas as mudanças ocorridas. Ressalta-se que a aplicação de estratégias de preservação, a mudança no licenciamento do objeto digital ou nos direitos autorais do objeto, devem ser acompanhadas da atualização dos metadados afetados por esta.

\subsection{Documentos a serem produzidos}

Alguns documentos orientadores são importantes de serem produzidos como resultado do planejamento, justamente porque abrangem boa parte das informações descritas na seção anterior. Aqui, destacam-se três deles.

O primeiro documento é o Plano de Preservação Digital (PPD) que é um documento estratégico que

... leva em consideração as políticas de preservação, obrigações legais, restrições organizacionais e técnicas, requisitos de usuários e objetivos de preservação e descreve o contexto da preservação, as estratégias de preservação avaliadas e a decisão resultante por uma estratégia, incluindo o raciocínio que levou a essa decisão. Também especifica uma série de etapas ou ações (chamadas de plano de ação de preservação), juntamente com responsabilidades, regras e condições para execução na coleção. Desde que as ações e sua implantação, bem como o ambiente técnico, permitam isso, esse plano de ação é uma definição de fluxo de trabalho executável. (PLANETS, 2006, p.3).

O PPD possui uma abordagem mais concreta e específica, constituindo, como já mencionado, um plano de ação a fim de garantir as condições mínimas de preservação para um determinado conjunto de objetos digitais de instituição/organização específica, levando 
em conta tantos as particularidades destas, quanto as especificidades dos objetos digitais sendo curados. Um guia útil para orientar a elaboração de planos de preservação digital foi elaborado pela Direção Geral do Livro, dos Arquivos e das Bibliotecas (DGLAB) (2019) e um bom exemplo de plano de preservação digital em vigor é o da Fundação Oswaldo Cruz (NASCIMENTO, 2020). Ressalta-se que a produção de um PPD deve ser o resultado de um esforço de colaboração entre a unidade orgânica responsável pela criação dos objetos digitais, profissionais da Ciência da Informação e área de Tecnologia, com a participação de representantes de todas as unidades orgânicas afetadas pelo processo de curadoria digital.

O segundo documento é um Manual, Cartilha ou Guia que oriente a descrição, representação da informação e contextualização dos objetos digitais a serem curados. Ou seja, oriente o preenchimento dos metadados de acordo com o padrão adotado para o projeto de curadoria (FORMETON, 2015) e com as especificidades dos objetos a serem curados. Metadados são informações estruturadas que descrevem, explanam, localizam, ou facilitam recuperar, usar ou gerenciar um recurso de informação (HODGE, 2000). Este documento se faz necessário para que haja uniformidade na compreensão das informações que precisam ser documentadas sobre os objetos sendo curados e o formato de preenchimento de cada elemento de metadados, de acordo com o padrão adotado. Um exemplo de documento deste tipo foi elaborado pela Fundação Oswaldo Cruz (2020).

E, por fim, no caso dos objetos digitais a serem curados serem dados de pesquisa, um documento orientador recomendado é o Plano de Gestão de Dados (PGD), que

... descreve, de uma forma geral, que dados serão processados, coletados ou gerados; quais
as metodologias e padrões que serão utilizados nesses processos; se, como e sob que
condições esses dados serão compartilhados e/ou tornados abertos para a comunidade de
pesquisa; e como eles serão curados e preservados (SAYÃO; SALES, 2015, p. 15).

Para compreender o contexto da gestão de dados de pesquisa e iniciar os estudos neste sentido, recomenda-se o Guia de Gestão de Dados de Pesquisa para Bibliotecários e Pesquisadores (SAYÃO; SALES, 2015). Ressalta-se que todos esses documentos precisam ser atualizados periodicamente, visto que o cenário em que são utilizados é dinâmico, como já mencionado.

Adicionalmente este é um bom momento para que sejam desenvolvidas políticas e normativas para todos os aspectos do processo de curadoria digital, de forma que sejam estabelecidos, de forma não ambígua, princípios, valores, papéis e intenções. Pois, desta maneira, decisões consistentes poderão ser tomadas com base no que estiver previamente estabelecido, contribuindo com a efetividade do processo de curadoria digital (HARVEY, 2010; OLIVER; HARVEY, 2016). De fato, ter políticas vigentes relacionadas 
à curadoria pode contribuir para a organização desenvolver estratégias para a curadoria digital e para que sejam realizados planejamentos coerentes de programas e projetos de curadoria digital.

Apesar do conteúdo das políticas poder diferir de acordo com a missão e as necessidades de cada instituição/organização, em geral, elas estabelecem: o que é permitido e o que não é; como a política será monitorada e quem é o responsável por este monitoramento. Elas também linkam outras políticas relevantes relacionadas e estabelecem procedimentos para realização das atividades de curadoria. Por fim, a política também precisa registrar a periodicidade de revisão dela própria, pois o contexto de sua aplicação é dinâmico (o contexto tecnológico evolui, o perfil do público-alvo pode mudar, etc) e pode requerer ajustes (OLIVER; HARVEY, 2016; BRASIL, 2019). Recomendações sobre como políticas de preservação podem ser elaboradas podem ser encontradas em BRASIL (2019) e um exemplo de política de preservação é a desenvolvida pelo Arquivo Nacional (BRASIL, 2016).

\subsection{A Abordagem da Etapa de Planejamento em Alguns Modelos de Curadoria Digital}

Tomando como base as dimensões definidas para o planejamento, verificou-se como a etapa de planejamento vem sendo abordada em alguns do principais modelos de ciclo de vida utilizados para curadoria digital, conforme o levantamento bibliográfico realizado.

O Open Archival Information System (OAIS) (OLIVEIRA, 2012; LAVOIE, 2014) é um modelo conceitual que descreve o ambiente, os componentes funcionais e os objetos de informação associados a um sistema responsável pela preservação de longo prazo. Neste modelo, a função de Planejamento da Preservação (preservation planning) engloba o desenvolvimento de estratégias de preservação, monitoramento da tecnologia adotada e outras atividades políticas e de planejamento. Apesar de não estar definido em um único lugar todas as dimensões do planejamento, sua estrutura de pacotes e a união dos modelos que o compõe trazem diversos dos elementos daquelas dimensões como 0 planejamento da criação dos objetos digitais e do acesso e uso dos mesmos.

O Joint information systems committee model (JISC) foi utilizado primariamente para publicação acadêmica e resulta de algumas adaptações e simplificações do modelo OAIS (BEAGRIE, 2004). Este modelo captura o objeto digital, garante seu armazenamento local e a replicação do mesmo em um armazenamento remoto (sistema de informação distribuído confiável), possui uma etapa de planejamento da preservação e, finalmente, promove o acesso ao objeto digital curado, sempre que ele for requisitado (BEAGRIE, 2004). O modelo aborda apenas o planejamento da preservação por meio 
da definição de estratégias de preservação, de como serão aplicadas, com que periodicidade e quem se responsabilizará pela sua aplicação (BEAGRIE, 2004). Apesar da escolha da estratégia impactar em questões de infraestrutura e recursos humanos, essas questões não são explicitamente especificadas. De fato, o modelo descreve de forma muito sucinta a etapa.

O Modelo de Ciclo de vida do DCC (c2004-2020) foi utilizado primeiramente para dados de pesquisa, mas é considerado um modelo genérico que pode ser adaptado a qualquer contexto. Tem 0 objeto digital em seu centro e usa uma abordagem em forma de ciclo de vida, subdividida em três tipos de ações: para toda vida, sequenciais e ocasionais. Frisa que nem todas as ações precisam ser realizadas, dependendo do contexto da instituição/organização. No modelo do DCC a etapa de planejamento está atrelado explicitamente à ação para toda vida de planejamento da preservação, onde devem ser criados planos para o gerenciamento e administração de todas as ações envolvidas nesta etapa, a revisão dos procedimentos curatoriais, a criação de políticas públicas que assegurem o desenvolvimento do projeto de curadoria, bem como, o levantamento dos gastos necessários à aplicação do projeto e a importância da gestão dos riscos e sua aplicação para garantir acesso ao longo do tempo aos objetos digitais. Todas essas prerrogativas devem ser elucubradas antes da iniciação de um projeto de curadoria. (OLIVER, HARVEY, 2016). Além disso, nas demais ações para toda vida são realizadas definições que serão aplicadas nas ações sequenciais e, que mesmo não explicitamente descritas ou mencionadas de forma sucinta, abordam elementos de praticamente todas as dimensões de planejamento anteriormente descritas (ex: planejamento da descrição e representação dos objetos digitais e o planejamento de como fornecer o acesso à informação). Um ponto interessante destacado no modelo é a ideia de envolver a comunidade alvo no processo de curadoria, desde o planejamento. Também no modelo é definida uma ação ocasional de reavaliação, onde o planejamento pode ser revisado.

DCC\&U - Extended digital curation lifecycle model (CONSTATOUPOULOS et al., 2009) É uma extensão do modelo do DCC, que considera e valoriza a informação contextual como forma de agregar valor ao objeto digital. Além disso, nesse modelo também acrescentou-se o registro das interações entre os usuários e os recursos digitais e os efeitos dessas interações, a fim de utilizar essa informação para aprimorar a disponibilização dos objetos digitais aos usuários. (CONSTANTOPOULOS et al., 2009). Como é uma extensão do modelo do DCC, a etapa de planejamento tem as mesmas características da do DCC, acrescido do fato que é levado em conta no planejamento os feedbacks obtidos a partir do uso do ambiente de disseminação da informação, de forma que melhorias possam ser incorporadas ao processo. 
O UK Data Archive Data Lifecycle (2010) foi utilizado inicialmente para dados de pesquisa e é composto por seis etapas: a criação, processamento, análise, preservação, acesso e reutilização dos dados. Este modelo apresenta o planejamento acoplado à ação de criação de dados, como uma subatividade, em paralelo com diversas outras, tais como localizar os dados existentes, coletar dados, capturar e criar metadados, entre outras. A subatividade "Planejar o gerenciamento dos dados (formatos, armazenamento, suporte, outros)" e "Compartilhamento do Planejamento" são as que diretamente mencionam o planejamento e focam, mesmo que parcialmente, no planejamento da preservação. Um possível problema do modelo é a ação ocorrer no mesmo momento em que elementos de planejamento devem ser definidos.

DataOne Data Lifecycle (2012) é utilizado para dados de pesquisa. O modelo possui oito etapas: planejar, coletar, garantir/assegurar a qualidade dos dados, descrever os dados, preservar, descobrir dados úteis, integrar esses dados e analisa-los. Na etapa Planejar é especificada a necessidade de definir quais dados serão gerenciados, qual repositório será utilizado, quanto do orçamento será destinado ao processo de curadoria, quem serão as pessoas responsáveis e pelo que estarão responsáveis e, assim, estabelecer as ações a serem colocadas em prática nas etapas seguintes (SILVA; SIEBRA, 2017). Verifica-se que o especificado nessa ação remete à criação do Plano de Gestão de Dados, condizente com a origem de aplicação do modelo, que são os dados de pesquisa. Também este modelo não aborda todas as dimensões do planejamento.

Verificou-se que os modelos de curadoria digital (SILVA; SIEBRA, 2017), talvez por terem suas bases no OAIS, focam muito mais no planejamento relacionado à preservação digital, deixando de fora a descrição explícita de questões voltadas para infraestrutura, recursos humanos e financeiros, assim como o planejamento do acesso aos dados. O que pode levar a um planejamento incompleto. Também verifica-se que, com exceção dos modelos DCC e DCC\&U, não é explicitada a importância da participação da comunidade alvo no planejamento. Essa participação pode ser um diferencial, visto que a comunidade alvo pode contribuir no planejamento com a descrição e contextualização dos objetos digitais, assim como com o planejamento do acesso e uso dos mesmos.

\section{CONSIDERAÇÕES FINAIS}

A curadoria digital não envolve apenas questões tecnológicas, mas diversos aspectos dos quais alguns se relacionam com práticas e compromissos administrativos já presentes na maior 
parte das instituições/organizações, tais como a gestão de recursos humanos e financeiros, as iniciativas de transparência ativa, a gestão de documentos, entre outros (PIRES; ROCHA, 2020). Justamente devido à diversidade de elementos envolvidos em um projeto de curadoria, este precisa ser bem planejado, de modo a mitigar os riscos de problemas ocorrerem ou do projeto não ser sustentável a longo prazo. O que poderia ser um grande problema visto que, a priori, projetos de curadoria devem ser desenvolvidos "para toda a vida", uma vez que podem existir objetos digitais que requerem preservação permanente.

Dessa forma, o planejamento pode direcionar a preparação, organização, estruturação e implementação de projetos de curadoria. Ele deve abranger questões técnicas, tecnológicas, legais e a definição dos recursos necessários (infraestrutura, humanos e financeiros), a fim de minimizar ou contornar possíveis problemas que possam se apresentar durante a implementação de projetos de curadoria. Para contribuir neste sentido, neste artigo foram apresentadas seis dimensões que devem ser exploradas no planejamento para curadoria digital, independente do tipo de objeto digital a ser curado, foram elas: infraestrutura, recursos financeiros, recursos humanos, ações relacionadas com preservação digital, questões legais e éticas e questões relacionadas ao acesso e uso dos objetos digitais. Também foram indicados documentos que devem ser produzidos durante o planejamento, a fim de orientar as equipes do projeto e foi ressaltada a importância da participação da comunidade alvo do projeto de curadoria nesta etapa, visando auxiliar nas decisões a serem tomadas (por exemplo, formas de descrição dos objetos, de disponibilização para o acesso, usos que podem ser feitos dos objetos digitais, etc). Além do fato que a comunidade alvo, em especial os produtores da informação, detém o conhecimento necessário para realizar a descrição e representação da informação, de forma a aprimorar sua recuperação e uso.

Adicionalmente foi verificado que as descrições sobre planejamento, na maioria dos modelos de curadoria digital (considerando os artigos sobre os mesmos e os sites de referência), é ainda sucinta e superficial e podem não dar apoio suficiente para a realização do planejamento por parte das instituições/organizações. Logo, é necessário que os profissionais da informação estejam aptos elaborar materiais para suprir essa lacuna e para orientar a implementação de projetos de curadoria digital.

Como trabalho em andamento estão sendo analisadas e detalhadas todas as principais etapas que existem em comum nos ciclos de curadoria, visando deixá-los mais claros e compreensíveis para quem necessite implementá-los na prática. 


\section{AGRADECIMENTOS}

O presente trabalho foi realizado com o apoio da Coordenação de Aperfeiçoamento de Pessoal de Nível Superior - Brasil (CAPES) - Código de Financiamento 001.

\section{REFERÊNCIAS}

ABBOTT, D. DCC Briefing Paper: What is digital curation? Edinburgh, UK: Digital Curation Centre, 2008. 4 p. Disponível em: https://era.ed.ac.uk/handle/1842/3362 . Acesso em: 15 nov. 2020.

ARELLANO, M. A. M. Preservação de documentos digitais. Ciência da Informação, 2004, v. 33, n. 2 , p. 15-27. Disponível em: http://revista.ibict.br/ciinf/article/view/1043 . Acesso em: 15 nov. 2020.

BARATEIRO, J.; ANTUNES, G.; FREITAS, F.; BORBINHA, J. Designing digital preservation solutions: A risk management-based approach. International Journal of Digital Curation, v. 5, n. 1, 2010, pp. 417. Disponível em: https://doi.org/10.2218/ijdc.v5i1.140. Acesso 14 nov. 2020.

BEAGRIE, N. The continuing access and digital preservation strategy for the UK Joint information systems committee (JISC) D-Lib Magazine, v.10, n.7/8. 2004. Disponível em: http://www.dlib.org/ dlib/july04/beagrie/07beagrie.html. Acesso em: 15 nov. 2020.

BRASIL. Ministério da Justiça. Arquivo Nacional. Política de Preservação Digital. Arquivo Nacional, 2016. http://www.siga.arquivonacional.gov.br/images/an_digital/and_politica_preservacao_digital_ v2.pdf . Acessado 14 nov. 2020.

BRASIL. Ministério da Justiça. Arquivo Nacional. Recomendações para elaboração de política de preservação digital. Arquivo Nacional, 2019. http://www.arquivonacional.gov.br/images/COGED/ Politica_presercacao_digital.pdf. Acessado 14 nov. 2020.

CAPLAN, P. Re:[digital-curation] Semantics: Digital Preservation vs. Digital Curation [15 de jul. de 2011 12:31:01]. 2011. Disponível em: https://groups.google.com/g/digital-curation/c/ ehppkZT9XGs?pli=1. Acesso em: 11 nov. 2020.

CHIAVENATO, I. Administração nos novos tempos: os novos horizontes em administração. 3. ed. Barueri, SP: Manole, 2014.

CONSTANTOPOULOS, P. et al. DCC\&U: An Extended Digital Curation Lifecycle Model. The International Journal of Digital Curation. n. 1, vol. 4. 2009. Disponível em: http://www.ijdc.net/article/ view/100. Acesso em: 15 nov. 2020.

DATA OBSERVATION NETWORK FOR EARTH - Data Life Cycle. 2012. Disponível em: https://www. dataone.org/data-life-cycle. Acesso em: 15 nov. 2020.

DATA SHARING FOR DEMOGRAPHIC RESEARCH - DSDR. 2008. Disponível em: https://www.icpsr. umich.edu/icpsrweb/content/DSDR/index.html . Acesso em: 15 nov. 2020. 
DIGITAL CURATION CENTRE (DCC). Curation Lifecycle Model Edinburgh: University of Edinburgh, c2004-2020. Disponível em: https://www.dcc.ac.uk/guidance/curation-lifecycle-model . Acesso em: 15 nov. 2020.

DIREÇÃO GERAL DO LIVRO, DOS ARQUIVOS E DAS BIBLIOTECAS (DGLAB). Recomendações para a produção de planos de preservação digital. $2^{2}{ }^{\underline{a}}$ versão. República Portuguesa, Agosto, 2019. Disponível em: http://arquivos.dglab.gov.pt/wp-content/uploads/sites/16/2014/02/Recomend_ producao_PPD_V2.1.pdf. Acesso em 15 nov. 2020.

FERREIRA, M. Introdução à Preservação digital: Conceitos, estratégias e atuais consensos. Guimarães: Escola de Engenharia da Universidade do Minho, 2006. 85p. Disponível em: https:// repositorium.sdum.uminho.pt/bitstream/1822/5820/1/livro.pdf . Acesso em: 15 nov. 2020.

FORMENTON, D. Identificação de padrões de metadados para preservação digital. 2015. 102 f. Dissertação (Mestrado em Ciência, Tecnologia e Sociedade) - Centro de Educação e Ciências Humanas, Universidade Federal de São Carlos, São Carlos, 2015.

FUNDAÇÃO OSWALDO CRUZ (FIOCRUZ). Manual de tratamento de dados: preenchimento dos metadados-recursos educacionais abertos. 2. ed. rev. e atual -- Rio de Janeiro: FIOCRUZ/ICICT, 2020.135p. Disponível em: https://www.arca.fiocruz.br/handle/icict/40162

GRACIO, J.C.A. Preservação digital na gestão da informação: um modelo processual para as instituições de ensino superior. 2011. 223 f. Tese (doutorado) - Universidade Estadual Paulista, Faculdade de Filosofia e Ciências de Marília, 2011.

HARVEY, R. Digital Curation: a how-to-do-it manual. New York: Neal-Schuman, 2010.

HIGGINS, S. Digital curation: the emergence of a new discipline. The International Journal of Digital Curation, v. 6, n. 2, 2008. Disponível em: http://www.ijdc.net/index.php/ijdc/article/view/184. Acesso em: 15 nov. 2020.

HODGE, G. Systems of knowledge organization for digital libraries: beyond traditional authorities files. Washington, DC: CLIR, 2000.

INTER-UNIVERSITY CONSORTIUM FOR POLITICAL AND SOCIAL RESEARCH - ICPSR. Guide to Social Science Data Preparation and Archiving: Best Practice Throughout the Data Life Cycle. Institute for Social Research University of Michigan. 3를 ed., 2005. Disponível em: https://deepblue.lib.umich.edu/bitstream/handle/2027.42/61289/ICPSR_dataprep_ pdf;jsessionid=BEA24BF87DC61AA03EEE45122876C5C2? sequence=1. Acesso em: 15 nov. 2020.

JOHNSTON, L. R. Curating Research Data, Volume One: Practical Strategies for Your Digital Repository. Chicago: ACRL, 2017. 294p.

KOWALCZYK, S. T. Digital Curation for Libraries and Archives. Santa Barbara, Califórnia. Libraries Unlimited. 2018.

LAVOIE, B. The Open Archival Information System (OAIS) Reference Model: Introductory Guide (2nd Edition). DPC Technology Watch Report 14-02 October 2014. DPC Technology Watch Series, 
2014. Disponível em: https://www.dpconline.org/docs/technology-watch-reports/1359-dpctw14-02/ file. Acesso em: 15 nov. 2020.

LEE, C. A.; TIBBO, H. Where's the Archivist in Digital Curation? Exploring the Possibilities through a Matrix of Knowledge and Skills. Archivaria, v. 72, p.123-168, 2011. Disponível em: https://ils.unc. edu/callee/p123-lee.pdf . Acesso em: 15 nov. 2020.

MAXIMIANO, A. C. A. Introdução à Administração. 7. ed. rev. e ampl. São Paulo: Atlas, 2010.

MELLO, J. Proposta de Modelo para a Preservação e Curadoria Digital de Objetos Digitais de Centros de Pesquisas Oncológicas. Tese de Doutorado (Programa de Pós-Graduação em Ciência da Informação). Centro De Ciências da Educação. UFSC: Florianópolis, 2020.

MICHEL. M. H. Metodologia e Pesquisa científica em ciências sociais: um guia prático para acompanhamento da disciplina e elaboração de trabalhos monográficos. 3. ed. Rev. e ampl. São Paulo: Atlas, 2015.

NASCIMENTO, A. F. G. Plano de Preservação Digital: Arca - Repositório Institucional -- Rio de Janeiro, Fundação Oswaldo Cruz/ICICT, 2020. 20 p.

NATIONAL ACADEMY OF SCIENCES. Preparing the Workforce for Digital Curation. Washington, DC: The National Academies Press, 2015. 104p.

OLIVER, G.; HARVEY, R. DIGITAL CURATION. 2ª ed. Chicago: ALA Neal-Schuman. American Library Association. 2016.

OLIVEIRA, D. P. R. Planejamento Estratégico: conceitos, metodologia e práticas. 34aa ed. São Paulo: Atlas, 2018.

OLIVEIRA, A.F. et al. 0 modelo de referência OAIS e a preservação digital distribuída. Ci. Inf., Brasília, DF, v.41 n.1, p.65-73, jan./abr., 2012. Disponível em: https://www.brapci.inf.br/_ repositorio/2014/11/pdf_20ae7f8b97_0031823.pdf. Acesso em: 15 nov. 2020.

PLANETS. Preservation Plan Template. [S.I.:s.n.], 2006. Disponível em: http://www.ifs.tuwien.ac.at/ dp/plato/docs/plan-template.pdf. Acesso em: 15 nov. 2020.

RIMKUS, K., PADILLA, T., POPP, T.; MARTIN, G. Digital Preservation File Format Policies of ARL Member Libraries: An Analysis. D-Lib Magazine, v.20, n.3, 2014. Disponível em: http://www.dlib.org/ dlib/march14/rimkus/03rimkus.html. Acesso em: 15 nov. 1010.

RONCAGLIO, C. et al. Arquivos, gestão de documentos e informação. Encontros Bibli: R. Eletr. Bibl. Ci. Inf. Florianópolis: 2004, n. esp., vol: jun.dez, p.1-13.

RUSBRIDGE, C; BURNHILL, P.; ROSS, S; BUNEMAN, P.; GIARETTA, D.; LYON, L.; ATKINSON, M. The Digital Curation Centre: A vision for digital curation. Data Interoperability - Challenges and Technologies, v. 26, p. 2007, 2005. Disponível em: https://ieeexplore.ieee.org/abstract/ document/1612461. Acesso em 15 nov. 2020. 
SANCHEZ, F. A.; VIDOTTI, S. A. B. G.; VECHIATO, F. L. A Contribuição da Curadoria Digital em Repositórios Digitais. Revista Informação na Sociedade Contemporânea, v. 1, p. 1-17, 11 jun. 2017. Disponível em: https://periodicos.ufrn.br/informacao/article/view/12280/8508. Acesso em 15 nov. 2020.

SANTOS, T. N. C. Curadoria digital: o conceito no período de 2000 a 2013. 2014. 165 f. Dissertação (Mestrado em Ciência da Informação) - Programa de Pós-Graduação em Ciência da Informação, Universidade de Brasília, Brasília, 2014.

SAYÃO, L. F.; SALES, L. F. Guia de Gestão de Dados de Pesquisa para Bibliotecários e Pesquisadores. Rio de Janeiro : CNEN/IEN, 2015.

SIEBRA, S. A.; BORBA, V. R.; MIRANDA, M. K. F. O. Curadoria digital: um termo interdisciplinar. Informação \& Tecnologia - Especial Enancib 2016 - parte 2. v. 3 n. 2, 2016. p.1-17. Disponível em: https://periodicos.ufpb.br/index.php/itec/article/view/38408 . Acesso em 15 nov. 2020.

SIEBRA, S. A.; BORBA, V. R. Análise, tendências e perspectivas da produção científica em curadoria digital. In: OLIVEIRA, Henry Poncio Cruz de; VIDOTTI, Silvana Aparecida Borsetti Gregório(org.). Informação e Tecnologias: desenhando fronteiras científicas. João Pessoa: Editora UFPB, 2018. p. 97-112.

SILVA, F. M.O. Curadoria Digital: Recomendações para acervos de objetos culturais digitais. Dissertação de mestrado (Programa de Pós-Graduação em Ciência da Informação). UFPE: Recife, 2017.

SILVA, F. M.O.; SIEBRA, S. A. Análise de modelos de ciclos de vida para curadoria digital de objetos digitais. In: XVIII Encontro Nacional de Pesquisa em Ciência da Informação (ENANCIB), 18, 2017, Marília, SP. Anais... Disponível em: http://enancib.marilia.unesp.br/index.php/xviiienancib/ENANCIB/ paper/viewFile/615/875. Acesso em 15 nov. 2020.

TAMMARO, A. M.; SALARELLI, A. A biblioteca digital. Tradução de Antonio Agenor Briquet de Lemos. Brasília, DF: Briquet de Lemos, 2008.

TAVARES, A. L.L. Análise de risco e preservação digital: uma abordagem sistêmica na Rede Memorial de Pernambuco. Dissertação (Mestrado). Programa de Pós-graduação em Ciência da Informação. UFPE, Recife, 2014.

TAVARES, A. L. L.; LIMA, M. G. Processos de preservação digital na rede memorial pernambuco (rmp). Informação \& Tecnologia, v. 4, n. 2, p. 163-184, 2017. Disponível em: http://hdl.handle. net/20.500.11959/brapci/101622. Acesso em: 15 nov. 2020.

TIBBO, H. R.; HANK, C.; LEE, C. A. Challenges, curricula, and competencies: researcher and practitioner perspectives for informing the development of a digital curation curriculum. In: ARCHIVING 2008, Bern, 2008. Final Program and Proceedings. Springfield: Society for Imaging Science and Technology, 2008.

UK DATA ARCHIVE. Create \& Manage Data: formatting your data. 2010. Disponível em: http://dataarchive.ac.uk. Acesso em 15 nov. 2020.

YAKEL, E. Digital Curation. OCLC Systems and Services: International digital library perspectives, v. 23, n. 4, p. 335-340, 2007. 